remaining $80 \mathrm{ml}$ is injected. According the authors in patients with hematuria, split-bolus MDCT- urography and oral hydration provide complete opacification of the majority of upper urinary tract segments and are accurate for the diagnosis of upper tract urothelial tumors. Since the main objective of MDCT-urography is to detect all possible causes of hematuria, this study has some limitations. The authors did no include an analysis of the capability of split-bolus technique for the detection of urinary calculi, renal parenchymal tumor and bladder cancers. As we know small bladder cancer can be missed if only excretory phase of the full bladder is obtained.

Another issue that could be addressed is how the renal parenchymal masses can be adequately characterized by the combined nephrographic /excretory phase obtained with split-bolus technique. Classically, renal masses are best characterized by the combination of findings obtained without intravenous contrast enhancement, scans obtained in nephrographic phase (70-90") and scans obtained in the excretory phase. In our opinion split bolus MDCT- urography may be useful for follow up patients with higher risk of develop upper tract urothelial cancer, particularly those already evaluated with cistoscopy. These patients should benefit with the use of this examination, which has high accuracy for the detection of urothelial cancer and uses low dose of radiation.

Dr. Adilson Prando

Head, Department of Radiology and

Diagnostic Imaging, Vera Cruz Hospital

Campinas, São Paulo, Brazil

E-mail: adilson.prando@gmail.com

\title{
PATHOLOGY
}

doi: $10.1590 /$ S1677-553820100002000020

\section{Should pathologists continue to use the current pT2 substaging system for reporting of radical prostatectomy specimens?}

Billis A, Meirelles L, Freitas LL, Magna LA, Ferreira U

Department of Anatomic Pathology, School of Medicine, University of Campinas, Unicamp, Brazil

Mod Pathol. 2010; 23 (suppl 1): 179A

Background: During the International Society of Urological Pathology (ISUP) consensus conference on handling and staging of radical prostatectomy specimens, $65.5 \%$ of the attendants answered that the current pT2 susbstaging system should not be used. Answering to another question, $63.4 \%$ favored to be reduced to two categories based on studies showing that $\mathrm{pT} 2 \mathrm{~b}$ does not exist. There was no consensus in regard to a minimum size for a second tumor to be considered for the whole case to be classified as pT2c as well as in regard to the definition of index tumor. We compared clinicopathologic findings and biochemical progression following surgery classifying pT2 patients into two categories.

Design: The study was based on whole-mount consecutive surgical specimens from 142 patients with organ confined cancer. Using a semiquantitative method for evaluation of tumor extent, 10 positive points corresponds roughly to a $0.5 \mathrm{ml}$ tumor. We considered $\mathrm{pT} 2 \mathrm{a} / \mathrm{pT} 2 \mathrm{~b}$ substage (group 1 ) whenever a tumor presented $>10$ positive points on only one side and pT2c whenever presented $>10$ positive points on each of right and left side (group 2). The variables analyzed were: age, preoperative PSA, clinical stage, Gleason score on needle biopsy, and biochemical progression following surgery defined as PSA $>0.2 \mathrm{ng} / \mathrm{mL}$. The data were analyzed using 
the Mann-Whitney test, and the Kaplan-Meier product-limit analysis using the log-rank test for comparison between the groups.Results: Substage pT2a/pT2b corresponded to 84/142 (59.2\%) patients and substage pT2c to $58 / 142(40.8 \%)$ patients. There was no statistically significant difference between the groups in relation to: age $(\mathrm{p}=0.30)$, preoperative PSA $(\mathrm{p}=0.13)$, clinical stage $(\mathrm{p}=0.34)$, and Gleason score on needle biopsy $(\mathrm{p}=$ 0.27 ). In 5 years of follow-up, $61 \%$ of patients pT2a/pT2b and $71 \%$ of patients $\mathrm{pT} 2$ were free of biochemical progression (log-rank, $\mathrm{p}=0.68$ ).

Conclusions: There was no significant difference for several clinicopathological variables and time of biochemical progression following surgery between patients with stage pT2a/pT2b and patients with stage pT3c. The results of this study favor to discontinue using the current pT2 substaging system for reporting of radical prostatectomy specimens.

\section{Editorial Comment}

In 1997, the TNM staging of T2 prostate cancers was divided into T2a (unilateral tumor) and T2b (bilateral tumor). In 2002 and now in 2010, T2 stage was substaged as in 1992, i.e., into 3 groups: T2a (unilateral tumor, less than half lobe), T2b (unilateral tumor, more than half lobe), and T2c (bilateral tumor). The clinical staging of T2 prostate cancers gives a good prognostic information. Time of biochemical (PSA) recurrence shows significant difference among the 3 groups. The clinical staging is a reflection of the detection methods employed and the substaging of clinical stage T2 prostate cancers is largely based on the extent of the abnormality palpated during a digital rectal examination (DRE) or shown during transrectal ultrasonography (TRUS) in each half of the prostate.

In a Consensus Meeting held during the United States and Canadian Academy of Pathology meeting in Boston 2009, 65.5\% of the uropathologists present answered that the current pathologic T2 substaging should not be continued. Why the pathologic T2 substaging should be discontinued?

In contrast to clinical substaging of T2 cancers, pathological substaging does not convey prognostic information. This happens because prostate cancer is essentially a multifocal tumor. In general, there is a larger tumor (index tumor) but almost always, other foci scattered along the gland. Therefore, a large unilateral tumor palpated by the urologist (cT2b) is always bilateral in the surgical specimen (pT2c) (1-3). It has been argued that the prognostic significance of clinical substaging by DRE and TRUS of T2 cancers is a direct effect of understaging (4). The paper surveyed was a platform presentation at the 99th Annual Meeting of the United States and Canadian Academy of Pathology held in Washington DC, 2010, and is supported by several other previous studies (5-8). The conclusions included no significant difference for several clinicopathological variables and time of biochemical progression following surgery between patients with pathologic stage T2a/pT2b and patients with pathologic stage T3c. The results of the study favor to discontinue using the current pathologic T2 substaging system for reporting of radical prostatectomy specimens.

\section{References}

1. Eichelberger LE, Cheng L: Does pT2b prostate carcinoma exist? Critical appraisal of the 2002 TNM classification of prostate carcinoma. Cancer. 2004; 100: 2573-6.

2. Quintal MM, Magna LA, Guimaraes MS, Ruano T, Ferreira U, Billis A: Prostate cancer pathologic stage pT2b (2002 TNM staging system): does it exist? Int Braz J Urol. 2006; 32: 43-7.

3. van Oort IM, Witjes JA, Kok DE, Kiemeney LA, Hulsbergen-Van De Kaa CA: The prognostic role of the pathological T2 subclassification for prostate cancer in the 2002 Tumour-Nodes-Metastasis staging system. BJU Int. 2008; 102: $438-41$.

4. van der Kwast TH: Substaging pathologically organ confined (pT2) prostate cancer: an exercise in futility? Eur Urol. 2006; 49: 209-11.

5. May F, Hartung R, Breul J: The ability of the American Joint Committee on Cancer Staging system to predict progression-free survival after radical prostatectomy. BJU Int. 2001; 88: 702-7. 
6. Freedland SJ, Partin AW, Epstein JI, Walsh PC: Biochemical failure after radical prostatectomy in men with pathologic organ-confined disease: pT2a versus pT2b. Cancer. 2004; 100: 1646-9.

7. Chun FK, Briganti A, Lebeau T, Fradet V, Steuber T, Walz J, et al.: The 2002 AJCC pT2 substages confer no prognostic information on the rate of biochemical recurrence after radical prostatectomy. Eur Urol. 2006; 49: 273-8; discussion 278-9.

8. Hong SK, Han BK, Chung JS, Park DS, Jeong SJ, Byun SS, et al.: Evaluation of pT2 subdivisions in the TNM staging system for prostate cancer. BJU Int. 2008; 102: 1092-6.

Dr. Athanase Billis

Full-Professor of Pathology State University of Campinas, Unicamp

Campinas, São Paulo, Brazil

E-mail: athanase@fcm.unicamp.br

doi: 10.1590/S1677-553820100002000021

\section{Radical prostatectomy (RP) findings in cases with only intraductal carcinoma of the prostate (IDC-P) on needle biopsy}

Robinson BD, Epstein JI

Dep. of Pathology, The Johns Hopkins Hospital, Baltimore, MD, USA

Mod Pathol 2010; 23 (suppl 1): 215A

Background: When IDC-P is present on biopsy, it is usually seen with infiltrating acinar adenocarcinoma. In 2006, we reported 27 cases with IDC-P only on biopsy; however, only 6 cases had available RP findings.

Design: 82 men with IDC-P only on prostate biopsy were identified from the consult files of one of the authors. Follow-up information was available in 66 cases. 20 men were treated with RP, 17 radiation therapy (RT), 8 hormone therapy (HT), 13 RT and HT, 6 active surveillance, and 2 rebiopsy. An attempt was made to retrieve the slides of all $20 \mathrm{RP}$ cases.

Results: Of the 20 RP cases, 5 showed extraprostatic extension, 3 seminal vesicle invasion, 10 were organ-confined, and 2 showed extensive IDC-P only without identifiable invasive cancer. Of the 18 cases with invasive cancer, the average Gleason score (GS) was 7.8. 1 patient developed bone metastases 3 years post-RP, and 3 others were post-RP PSA failures. 13 RPs were available for our review. 9 showed extensive IDC-P (including one case of IDC-P only), defined as $>10 \%$ of the tumor volume being intraductal; 3 focal IDC-P; and 1 no IDC-P. All cases with invasive carcinoma were acinar, although 3 cases were classified as ductal by referring pathologists. We concurred with the outside GS in 5/13 cases ( 5 undergraded, 3 overgraded). In the 3 cases that we gave lower GS, the outside institution graded cribiform IDC-P with and without necrosis as Gleason pattern 5 or 4 , respectively.

Conclusions: Our study, the largest to date with RP findings following IDC-P only on needle biopsy, confirms that aggressive therapy is appropriate for patients whose biopsies show only IDC-P. It is likely that the pathological findings are even worse than we report herein, as most RPs were only partially sampled. Most cases likely represent intraductal spread of high grade cancer, but some cases represent in situ acinar adenocarcinoma.

\section{Editorial Comment}

Intraductal carcinoma of the prostate (IDC-P) is defined as presence of atypical cells that span the entire lumen of prostatic ducts or acini while the normal architecture of ducts or acini is still maintained including presence of basal cells $(1,2)$. With presence of IDC-P on a biopsy, the pathologist considers 4 possibilities: 1 ) 